\title{
ANTHROPOLOGISCHE/ARCHÄOZOOLOGISCHE TABELLE
}

Simon Kramis

Anhang zur Publikation : Lawrence Andy, Religion in Vindonissa (2018), Brugg.

\begin{tabular}{|c|c|c|c|c|c|c|c|c|c|c|c|c|}
\hline FK & Kn. Nr. & Pos. & Tierart & TierName & Tier & Skelettteil & SkelName & $\begin{array}{l}\text { Knochen- } \\
\text { teil }\end{array}$ & Alter1 & Alter2 & $\begin{array}{l}\text { Bruch- } \\
\text { kante }\end{array}$ & $\begin{array}{l}\text { Bruch- } \\
\text { kante2 }\end{array}$ \\
\hline 1535 & 3 & 130,2 & 20 & Sus domesticus & Hausschwein & 44 & Tibia & 15 & 25 & 1 & 0 & 0 \\
\hline 1535 & 15 & 130,2 & 20 & Sus domesticus & Hausschwein & 44 & Tibia & 1 & 25 & 10 & 0 & 0 \\
\hline 1535 & 4 & 130,2 & 20 & Sus domesticus & Hausschwein & 44 & Tibia & 7 & 25 & 10 & 0 & 0 \\
\hline 1535 & 4 & 130,2 & 20 & Sus domesticus & Hausschwein & 80 & Costa & 2 & 0 & & 0 & 0 \\
\hline 1535 & 4 & 130,2 & 5 & indet. Gr. Schwein & & 5 & Cranium & 20 & 0 & & 0 & 0 \\
\hline 1535 & 4 & 130,2 & 5 & indet. Gr. Schwein & & 91 & Plattenknochen indet. & 0 & 0 & & 0 & 0 \\
\hline 1535 & 9 & 130,2 & 20 & Sus domesticus & Hausschwein & 42 & Femur & 7 & 0 & & 0 & 1 \\
\hline 1535 & 21 & 130,2 & 20 & Sus domesticus & Hausschwein & 41 & Pelvis & 1 & 0 & & 0 & 1 \\
\hline 1535 & 21 & 130,2 & 5 & indet. Gr. Schwein & & 91 & Plattenknochen indet. & & & & 0 & 1 \\
\hline 1535 & 30 & 130,2 & 20 & Sus domesticus & Hausschwein & 44 & Tibia & 10 & 25 & 0 & 0 & 1 \\
\hline 1535 & 30 & 130,2 & 5 & indet. Gr. Schwein & & 91 & Plattenknochen indet. & & & & 0 & 1 \\
\hline 1535 & 32 & 130,2 & 20 & Sus domesticus & Hausschwein & 46 & Astragalus & 2 & 0 & & 0 & 1 \\
\hline 1535 & 32 & 130,2 & 20 & Sus domesticus & Hausschwein & 42 & Femur & 35 & 25 & 1 & 0 & 1 \\
\hline 1535 & 32 & 130,2 & 5 & indet. Gr. Schwein & & 91 & Plattenknochen indet. & & & & 0 & 1 \\
\hline 1535 & 32 & & & Homo sapiens & Mensch & & Talus & & erw. & & & \\
\hline 1535 & 27 & 130,2 & 20 & Sus domesticus & Hausschwein & 44 & Tibia & 31 & 0 & & 0 & 1 \\
\hline 1535 & 26 & 130,2 & 5 & indet. Gr. Schwein & & 90 & Röhrenknochen indet. & & 0 & & 0 & 1 \\
\hline 1535 & 29 & 130,2 & 99 & Homo sapiens & Mensch & 80 & Costa & 2 & erw. & & 0 & 1 \\
\hline 1535 & 16 & 130,2 & 99 & indet. & & 80 & Costa & 2 & 0 & & 0 & 1 \\
\hline 1535 & 5 & 130,2 & 99 & indet. & & 24 & Humerus & 29 & 0 & & 0 & 1 \\
\hline 1535 & 7 & 130,2 & 99 & indet. & & 24 & Humerus & 29 & 0 & & 0 & 1 \\
\hline 1535 & 10 & 130,2 & 99 & indet. & & 44 & Tibia? & 29 & & & 0 & 1 \\
\hline 1535 & 14 & 130,2 & 20 & Sus domesticus & Hausschwein & 42 & Femur & 21 & 25 & 10 & 0 & 1 \\
\hline 1535 & 28 & 130,2 & 1 & indet. & & 90 & Röhrenknochen indet. & & & & 0 & 1 \\
\hline 1535 & 28 & 130,2 & 20 & Sus domesticus & Hausschwein & 44 & Tibia & 27 & 0 & & 0 & 1 \\
\hline 1535 & 28 & 130,2 & 99 & indet. & & 90 & Röhrenknochen indet. & & 0 & & 0 & 1 \\
\hline 1535 & 28 & 130,2 & 99 & indet. & & 90 & Röhrenknochen indet. & & 0 & & 0 & 1 \\
\hline 1535 & 28 & 130,2 & 99 & indet. & & 90 & Röhrenknochen indet. & & & & 0 & 1 \\
\hline 1535 & 28 & 130,2 & 99 & indet. & & 90 & Röhrenknochen indet. & & & & 0 & 1 \\
\hline 1535 & 28 & 130,2 & 99 & indet. & & 80 & Costa & 2 & 0 & & 0 & 1 \\
\hline 1535 & 28 & 130,2 & 1 & indet. & & 93 & Spongiosateil indet. & & & & 0 & 1 \\
\hline 1535 & 28 & 130,2 & 1 & indet. & & 90 & Röhrenknochen indet. & & & & 0 & 1 \\
\hline 1535 & 28 & 130,2 & 1 & indet. & & 91 & Plattenknochen indet. & & & & 0 & 1 \\
\hline 1535 & 12 & 130,2 & 99 & indet. & & 75 & Sacrum & 1 & 0 & & 0 & 1 \\
\hline 1535 & 11 & 130,2 & 99 & indet. & & 90 & Röhrenknochen indet. & & & & 0 & 1 \\
\hline 1535 & 11 & 130,2 & 1 & indet. & & 90 & Röhrenknochen indet. & & & & 0 & 1 \\
\hline 1535 & 17 & 130,2 & 99 & indet. & & 90 & Röhrenknochen indet. & & & & 0 & 1 \\
\hline 1535 & 6 & 130,2 & 99 & indet. & & 91 & Plattenknochen indet. & & 0 & & 0 & 1 \\
\hline 1535 & 6 & 130,2 & 20 & Sus domesticus & Hausschwein & 42 & Femur & 26 & 25 & 10 & 0 & 0 \\
\hline 1535 & 6 & 130,2 & 99 & Homo sapiens & Mensch & 72 & Vertebrum cervicalis & 1 & Infans I-II & & 0 & 1 \\
\hline 1535 & 8 & 130,2 & 99 & indet. & & 93 & Spongiosateil indet. & & & & 0 & 1 \\
\hline 1535 & 2 & 130,2 & 99 & indet. & & 93 & Spongiosateil indet. & & 0 & & 0 & 1 \\
\hline 1535 & 2 & 130,2 & 99 & indet. & & 90 & Röhrenknochen indet. & & 0 & & 0 & 1 \\
\hline 1535 & 2 & 130,2 & 1 & indet. & & 5 & Cranium & & 0 & & 0 & 1 \\
\hline 1535 & 20 & 130,2 & 99 & indet. & & 80 & Röhrenknochen indet. & 2 & & & 0 & 1 \\
\hline 1535 & 20 & 130,2 & 200 & Aves indet & Vögel & 90 & Röhrenknochen indet. & & 0 & & 0 & 1 \\
\hline 1535 & 20 & 130,2 & 1 & indet. & & 90 & Röhrenknochen indet. & & & & 0 & 1 \\
\hline 1535 & 1 & 130,2 & 99 & indet. & & 93 & Spongiosateil indet. & & & & 0 & 1 \\
\hline
\end{tabular}




\begin{tabular}{|c|c|c|c|c|c|c|c|c|c|c|c|}
\hline Erhaltung & Wurzelfrass & Kruste & fettig & Patina & Brandspur & Verbiss & Geschlecht & Koerperseite & Gewicht & Objekt-Notiz & Anzahl \\
\hline 0 & 0 & 0 & 0 & 0 & 5 & 0 & indet & $r$ & 3,3 & & 1 \\
\hline 0 & 0 & 0 & 0 & 0 & 7 & 0 & indet & $r$ & 6,5 & & 1 \\
\hline 0 & 0 & 0 & 0 & 0 & 7 & 0 & indet & $r$ & 14,9 & & 1 \\
\hline 0 & 0 & 0 & 0 & 0 & 7 & 0 & indet & indet & 1,1 & & 1 \\
\hline 0 & 0 & 0 & 0 & 0 & 7 & 0 & indet & indet & 1,1 & & 1 \\
\hline 2 & 0 & 0 & 0 & 0 & 7 & 0 & indet & indet & 1 & & 1 \\
\hline 0 & 0 & 0 & 0 & 0 & 7 & 0 & indet & $r$ & 10,3 & & 1 \\
\hline 0 & 0 & 0 & 0 & 0 & 7 & 0 & indet & $r$ & 4,5 & & 1 \\
\hline 0 & 0 & 0 & 0 & 0 & 7 & 0 & indet & indet & 1,2 & & 6 \\
\hline 0 & 0 & 0 & 0 & 0 & 7 & 0 & indet & $r$ & 13,2 & & 1 \\
\hline 0 & 0 & 0 & 0 & 0 & 7 & 0 & indet & indet & 2,7 & & 6 \\
\hline 0 & 0 & 0 & 0 & 0 & 5 & 0 & indet & $r$ & 6,1 & & 1 \\
\hline 0 & 0 & 0 & 0 & 0 & 7 & 0 & indet & $r$ & 3,6 & & 1 \\
\hline 0 & 0 & 0 & 0 & 0 & 7 & 0 & indet & indet & 0,7 & & 1 \\
\hline & & & & & & & indet & & 5,3 & & 1 \\
\hline 0 & 0 & 0 & 0 & 0 & 7 & 0 & indet & $r$ & 2 & & 1 \\
\hline 0 & 0 & 0 & 0 & 0 & 7 & 0 & indet & indet & 5,5 & & 1 \\
\hline 0 & 0 & 0 & 0 & 0 & 7 & 0 & indet & indet & 3,8 & & 1 \\
\hline 0 & 0 & 0 & 0 & 0 & 7 & 0 & indet & indet & 9,7 & & 1 \\
\hline 0 & 0 & 0 & 0 & 0 & 7 & 0 & indet & indet & 10,5 & gehört zu Kn 7 & 1 \\
\hline 0 & 0 & 0 & 0 & 0 & 7 & 0 & indet & indet & 6,2 & gehört zu Kn 5 & 1 \\
\hline 0 & 0 & 0 & 0 & 0 & 7 & 0 & indet & indet & 4,7 & & 1 \\
\hline 0 & 0 & 0 & 0 & 0 & 7 & 0 & indet & $r$ & 3,1 & & 1 \\
\hline 0 & 0 & 0 & 0 & 0 & 7 & 0 & indet & indet & 1,9 & & 4 \\
\hline 0 & 0 & 0 & 0 & 0 & 7 & 0 & indet & $r$ & 4,7 & & 1 \\
\hline 0 & 0 & 0 & 0 & 0 & 7 & 0 & indet & indet & 4,5 & & 1 \\
\hline 0 & 0 & 0 & 0 & 0 & 7 & 0 & indet & indet & 2,3 & & 1 \\
\hline 0 & 0 & 0 & 0 & 0 & 7 & 0 & indet & indet & 3 & & 1 \\
\hline 0 & 0 & 0 & 0 & 0 & 7 & 0 & indet & indet & 1,2 & & 1 \\
\hline 0 & 0 & 0 & 0 & 0 & 7 & 0 & indet & indet & 2,1 & & 1 \\
\hline 0 & 0 & 0 & 0 & 0 & 7 & 0 & indet & indet & 2,4 & & 2 \\
\hline 0 & 0 & 0 & 0 & 0 & 7 & 0 & indet & indet & 4,4 & & 5 \\
\hline 0 & 0 & 0 & 0 & 0 & 7 & 0 & indet & indet & 1,1 & & 8 \\
\hline 0 & 0 & 0 & 0 & 0 & 7 & 0 & indet & indet & 9,6 & & 1 \\
\hline 0 & 0 & 0 & 0 & 0 & 7 & 0 & indet & indet & 9,6 & & 2 \\
\hline 0 & 0 & 0 & 0 & 0 & 7 & 0 & indet & indet & 0,2 & & 1 \\
\hline 0 & 0 & 0 & 0 & 0 & 7 & 0 & indet & indet & 5,4 & & 2 \\
\hline 0 & 0 & 0 & 0 & 0 & 7 & 0 & indet & indet & 7 & & 1 \\
\hline 0 & 0 & 0 & 0 & 0 & 7 & 0 & indet & indet & 3,6 & & 1 \\
\hline 0 & 0 & 0 & 0 & 0 & 7 & 0 & indet & indet & 1,1 & zweites, kleineres Individuum? & 1 \\
\hline 0 & 0 & 0 & 0 & 0 & 7 & 0 & indet & indet & 2,4 & & 1 \\
\hline 0 & 0 & 0 & 0 & 0 & 7 & 0 & indet & indet & 2 & & 1 \\
\hline 0 & 0 & 0 & 0 & 0 & 7 & 0 & indet & indet & 2,3 & & 1 \\
\hline 0 & 0 & 0 & 0 & 0 & 7 & 0 & indet & indet & 1,3 & & 2 \\
\hline 0 & 0 & 0 & 0 & 0 & 7 & 0 & indet & indet & 2,5 & & 1 \\
\hline 0 & 0 & 0 & 0 & 0 & 7 & 0 & indet & indet & 0,1 & & 1 \\
\hline 0 & 0 & 0 & 0 & 0 & 7 & 0 & indet & indet & 0,6 & & 5 \\
\hline 0 & 0 & 0 & 0 & 0 & 7 & 0 & indet & indet & 4,1 & & 5 \\
\hline
\end{tabular}




\begin{tabular}{|c|c|c|c|c|c|c|c|c|c|c|c|c|}
\hline FK & Kn. Nr. & Pos. & Tierart & TierName & Tier & Skelettteil & SkelName & $\begin{array}{l}\text { Knochen- } \\
\text { teil }\end{array}$ & Alter1 & Alter2 & $\begin{array}{l}\text { Bruch- } \\
\text { kante }\end{array}$ & $\begin{array}{l}\text { Bruch- } \\
\text { kante2 }\end{array}$ \\
\hline 1535 & 1 & 130,2 & 1 & indet. & & 99 & indet. & & & & 0 & 1 \\
\hline 1535 & 1 & 130,2 & 5 & indet. Gr. Schwein & & 90 & Röhrenknochen indet. & & & & 0 & 0 \\
\hline 1535 & 23 & 130,2 & 99 & indet. & & 93 & Spongiosateil indet. & & & & 0 & 1 \\
\hline 1535 & 23 & 130,2 & 1 & indet. & & 91 & Plattenknochen indet. & & & & 0 & 1 \\
\hline 1535 & 28 & 130,2 & 1 & indet. & & 90 & Röhrenknochen indet. & & & & 0 & 1 \\
\hline 1535 & 28 & 130,2 & 99 & indet. & & 93 & Spongiosateil indet. & & & & 0 & 1 \\
\hline 1535 & 31 & 130,2 & 1 & Homo sapiens & Mensch & 90 & Ulna/Radius? & & erw. & & 0 & 0 \\
\hline 1535 & 13 & 130,2 & 99 & indet. & & 90 & Röhrenknochen indet. & & 0 & & 0 & 1 \\
\hline 1535 & 13 & 130,2 & 99 & indet. & & 93 & Spongiosateil indet. & & & & 0 & 1 \\
\hline 1535 & 24 & 130,2 & 5 & indet. Gr. Schwein & & 93 & Spongiosateil indet. & & & & 0 & 1 \\
\hline 1535 & 24 & 130,2 & 1 & indet. & & 99 & indet. & & & & 0 & 1 \\
\hline 1535 & 19 & 130,2 & 99 & indet. & & 90 & Röhrenknochen indet. & & & & 0 & 1 \\
\hline 1535 & 26 & 130,2 & 99 & Homo sapiens & Mensch & 93 & Humerus/Femur? & & erw. & & 0 & 1 \\
\hline 1535 & 22 & 130,2 & 1 & indet. & & 93 & Spongiosateil indet. & & & & 0 & 1 \\
\hline 1535 & 25 & & & Homo sapiens & Mensch & & Humerus/Femur? & & erw. & & & \\
\hline 1535 & 25 & & & Homo sapiens & Mensch & & Pelvis Ilium? & & erw. & & & \\
\hline 1535 & 25 & & & Homo sapiens & Mensch & & Ulna/Radius? & & erw. & & & \\
\hline 1535 & 25 & & & Homo sapiens & Mensch & & Ulna/Radius? & & erw. & & & \\
\hline 1535 & 25 & & & indet. & & & Röhrenknochen indet. & & & & & \\
\hline 1535 & 18 & & & indet. & & & & & & & & \\
\hline TOTAL & & & & & & & & & & & & \\
\hline
\end{tabular}

Tab. 21 Brugg-Kabelwerke 2007-2008 (Bru.007.3). Anthropologische und archäozoologische Bestimmungen des verbrannten Knochenmaterials aus G1. 


\begin{tabular}{|c|c|c|c|c|c|c|c|c|c|c|c|}
\hline Erhaltung & Wurzelfrass & Kruste & fettig & Patina & Brandspur & Verbiss & Geschlecht & Koerperseite & Gewicht & Objekt-Notiz & Anzahl \\
\hline 0 & 0 & 0 & 0 & 0 & 7 & 0 & indet & indet & 1 & & 6 \\
\hline 0 & 0 & 0 & 0 & 0 & 7 & 0 & indet & indet & 1,4 & & 1 \\
\hline 0 & 0 & 0 & 0 & 0 & 7 & 0 & indet & indet & 5 & & 3 \\
\hline 0 & 0 & 0 & 0 & 0 & 7 & 0 & indet & indet & 0,1 & & 2 \\
\hline 0 & 0 & 0 & 0 & 0 & 7 & 0 & indet & indet & 2,2 & & 3 \\
\hline 0 & 0 & 0 & 0 & 0 & 7 & 0 & indet & indet & 1,8 & & 3 \\
\hline 0 & 0 & 0 & 0 & 0 & 7 & 0 & indet & indet & 3,5 & & 1 \\
\hline 0 & 0 & 0 & 0 & 0 & 7 & 0 & indet & indet & 2,1 & & 1 \\
\hline 0 & 0 & 0 & 0 & 0 & 7 & 0 & indet & indet & 0,3 & & 1 \\
\hline 0 & 0 & 0 & 0 & 0 & 7 & 0 & indet & indet & 2,3 & & 1 \\
\hline 0 & 0 & 0 & 0 & 0 & 7 & 0 & indet & indet & 0,2 & & 3 \\
\hline 0 & 0 & 0 & 0 & 0 & 7 & 0 & indet & indet & 1,7 & & 1 \\
\hline 0 & 0 & 0 & 0 & 0 & 7 & 0 & indet & indet & 1,8 & & 1 \\
\hline \multirow[t]{7}{*}{0} & 0 & 0 & 0 & 0 & 7 & 0 & indet & indet & 2 & & 9 \\
\hline & & & & & & & indet & indet & 2,6 & & 1 \\
\hline & & & & & & & indet & indet & 2,3 & & 1 \\
\hline & & & & & & & indet & indet & 2,2 & & 1 \\
\hline & & & & & & & indet & indet & 4,7 & & 1 \\
\hline & & & & & & & indet & indet & 12,1 & & 9 \\
\hline & & & & & & & indet & indet & 1,8 & & 3 \\
\hline & & & & & & & & & 251,5 & & 136 \\
\hline
\end{tabular}

